\title{
APROXIMAÇÃo da históRIa da MATEMÁtica PRESENTE NOS LIVROS DIDÁTICOS COM A ESCRITA HISTORIOGRÁFICA TRADICIONAL E ATUALIZADA
}

\author{
APPROXIMATION OF THE HISTORY OF MATHEMATICS PRESENT IN \\ TEXTBOOKS WITH TRADITIONAL AND UPDATED HISTORIOGRAPHICAL \\ WRITING
}

DOI: http://dx.doi.org/10.23926/RPD.2526-2149.2018.v3.n2.p406-417.id236

\section{Francisco Wagner Soares Oliveira \\ Mestrando em Ensino de \\ Ciências e Matemática \\ (IFCE).}

franciscowagner2007@gmail . $\mathrm{com}$

\section{Eugeniano Brito \\ Martins}

Professor EBTT (IFCE).

Mestrando em Ensino de

Ciências e Matemática

(IFCE).

eugenianobm@gmail.com

\section{Suziê Maria de \\ Albuquerque}

Mestranda em Ensino de

Ciências e Matemática

(IFCE).

Professora da Secretária de

Educação do Estado do

Ceará (SEDUC-CE).

suziealbuquerque@hotmail.c

om

\section{Ana Carolina Costa Pereira \\ Doutorado em Educação (UFRN). \\ Professora na Universidade Estadual do Ceará (UECE). carolina.pereira@uece.b}

Resumo: A história da matemática como campo de investigação cientifica tem possibilitado, por meio da observação e análise em tratados históricos que carregam em seu conteúdo e contexto uma gama de informações, a produção de narrativas historiográficas das quais são elencados desdobramentos para o ensino. Tal fato tem ocorrido a partir do pressuposto de que a incorporação de elementos da história em sala pode fornecer subsídios ao processo de ensino e aprendizagem. Visto isso, mediante a proximidade com a educação básica, em especial com o ensino médio, desenvolveu-se esse estudo na tentativa de identificar a aproximação das escritas baseadas na história da matemática presentes em livros didáticos do ensino médio com as vertentes historiográficas tradicional e atualizada. Nessa perspectiva, a pesquisa ora realizada foi de cunho qualitativa documental com uma contribuição bibliográfica. Verificou-se nesse estudo que os textos, em que informações da história são elucidadas, possuem características que condizem com a vertente historiográfica tradicional. Em nenhuma das alusões feitas à história foi possível observar um domínio de características que a indicasse como próxima a uma escrita da história nos moldes da vertente atualizada.

Palavras-chave: Ensino de matemática. Livro didático. Escrita da história da matemática.

\begin{abstract}
Tradução do resumo para o Inglês. The history of mathematics as a field of scientific investigation has made possible through observation and analysis in treaties and / or works that carry in their content and context a range of information to the production of some historiographical narratives, of which they are sometimes listed and / or some of its implications for teaching. This fact has occurred from the assumption that the incorporation of elements of the story into room may possibly provide subsidies to the teaching and learning process. Given this, and through proximity to basic education, especially with secondary education, this study was developed in an attempt to identify the approximation of the writings based on the history of mathematics present in high school textbooks with the traditional and updated historiographic aspect. From this perspective, the research carried out was qualitative documentary with a bibliographical contribution. It was mentioned in this study that the texts, in which information of the story are elucidated, have characteristics that correspond to the traditional historiographic aspect, in none of the allusions made history was it possible to observe a domain of characteristics that indicated it as close to a writing of history in the molds of the updated slope.
\end{abstract}

Keywords: Teaching mathematics. Textbook. Math history writing. 


\title{
1 INTRODUÇÃO
}

Partindo do pressuposto de que a história da matemática é um campo de investigação científica conforme destacado por Baroni e Nobre (1999), quanto à incorporação de alguns de seus elementos no ensino, observa-se que:

\begin{abstract}
Pesquisas atuais indicam que a inserção de fatos do passado pode ser uma dinâmica bastante interessante para introduzir um determinado conteúdo matemático em sala de aula, tendo em vista que o aluno pode reconhecer a Matemática como uma criação humana que surgiu a partir da busca de soluções para resolver problemas do cotidiano, conhecer as preocupações dos vários povos em diferentes momentos e estabelecer comparações entre os conceitos e processos matemáticos do passado e do presente. (CHAQUIAM, 2017, p. 14).
\end{abstract}

De acordo com Oliveira e Sousa (2017) tal indicação vai de encontro à concepção apresentada por professores da educação básica referente à incorporação de elementos da história no ensino de matemática. Como destacado pelos referidos autores, os educadores, sejam eles do ensino fundamental ou do ensino médio, entendem que tal inserção pode favorecer a assimilação dos conteúdos por parte dos alunos.

O ambiente favorável à incorporação da história no ensino possivelmente é o que tem feito com que ela venha sendo abordada em livros didáticos destinados à educação básica. No que se refere especificamente às coleções destinadas ao ensino médio. Pereira (2016) observou que nas seis coleções aprovadas pelo Programa Nacional do Livro Didático - PNLD 2015 todas as coleções de livros de matemática trazem em algum momento formas de escritas baseadas na história.

Assumindo tais escritas como peças fundamentais para que a história possa de fato vir a fornecer elementos que favoreçam o processo de ensino e aprendizagem, elas foram elencadas como objetos de investigação desta pesquisa.

Nesse sentido, observou-se em Saito (2015) que as historiografias (escritas da história) têm sido formuladas sobre duas vertentes. Uma mais antiga denominada de historiografia tradicional, a qual tem como característica apresentar em sua escrita a linearidade dos fatos históricos e outra mais recente, com características diferentes da anterior conhecida como historiografia atualizada.

Com base nas características historiográficas que a escrita da história pode assumir e, sabendo que, os livros didáticos do ensino médio apresentam escritas baseadas na história, elencou-se a seguinte questão investigativa para o estudo: qual a aproximação das escritas da história da matemática abordadas nos livros didáticos com a vertente historiográfica tradicional e com a atualizada? 
Com vistas a responder tal indagação, teve-se como objetivo identificar a aproximação das escritas baseadas na história da matemática presentes em livros didáticos do ensino médio com a vertente historiográfica tradicional e atualizada. Para tanto, a partir das características historiográficas de cada uma das vertentes mencionadas, foi observada uma coleção de livros didáticos aprovada pelo PNLD 2018.

\section{REFERENCIAL TEÓRICO}

O PNLD é o programa nacional que possibilita ao professor da educação básica ter acesso às coleções de livros didáticos já selecionadas por uma equipe educadores especializada, com base em uma série de princípios e de critérios estabelecidos em edital, de tal forma que a partir das especificidades de cada escola seja eleita uma delas como recurso a ser utilizado em sua prática.

Desse cenário, pesquisadores como Bianchi (2006), Cardoso e Zuin (2015), Biffi (2016), Pereira (2016), Vidal et al. (2016) e de Turíbio e Silva (2017) tratam que a história da matemática está de alguma forma presente na escrita de trechos dos livros. Entende-se que, possivelmente, esse fator satisfaça ou esteja ligado com princípios e critérios do PNLD 2018.

Nesse sentido, observou-se na ficha de avaliação dos livros com que os educadores selecionam as coleções a serem aprovadas pelo PNLD que o quinto item da lista avalia a abordagem empregada para estabelecer a contextualização e interdisciplinaridade dos conteúdos matemáticos om algumas práticas. Nos subitens 5.1.3 e 5.1.4, desse mesmo questionário, é indicado se as coleções realizam alguma abordagem que venha a favorecer a aprendizagem da matemática por meio da apresentação de seu contexto e das práticas sociais que a incorporam de forma que seja vista como uma criação humana ao longo da história (BRASIL, 2017).

Assim, entende-se estes itens de avaliação como um dos possíveis porquês de as coleções referenciar à história da matemática em suas obras. Nesse tocante, tem-se a seguinte consideração no guia de livros do PNLD 2018:

No caso de contextualizações ligadas à história da Matemática, há obras didáticas em que se encontram breves informações, com ênfase na identificação dos personagens envolvidos no desenvolvimento de um determinado tema e suas localizações no tempo histórico. No entanto, sabe-se que é possível atribuir significado a conteúdos matemáticos considerando-se tanto evolução histórica dos conceitos e de suas interrelações no âmbito da Matemática, quanto das motivações e necessidades sociais, econômicas e científicas que levaram ao avanço dessa ciência. (BRASIL, 2017, p. 40) 
Desse modo, subtende-se que a utilização da história como forma de buscar estabelecer uma contextualização pode ir desde uma mera apresentação dos principais personagens e suas contribuições para o estabelecimento de um determinado conteúdo até outras ferramentas mais elaboradas que busquem de fato, a partir do processo de construção do conhecimento matemático, trazer elementos que favoreçam a contextualização.

Nessa perspectiva, de forma a adentrar nas características de algumas das abordagens de escrita da história, dando destaque as vertentes historiográficas tradicional e atualizada, cabe observar inicialmente que:

Devemos aqui entender, por historiografia, a "escrita da história", e que toda narrativa da história da matemática é historiograficamente orientada. Isso significa que as narrativas históricas não são neutras e são influenciadas por diferentes fatores ligados à formação e à concepção de ciência (isto é, de conhecimento válido numa época) daquele que as escreve. (SAITO, 2015, p. 21).

Nesse sentido, se diferencia uma escrita caracterizada na vertente historiográfica tradicional da atualizada pelos fatores listados e assumidos pelo escritor do texto. No que concerne especificamente a vertente historiográfica tradicional, sabe-se que:

As grandes narrativas históricas são características da história da matemática de vertente tradicional. Essa história, caracteristicamente panorâmica, está baseada numa concepção historiográfica linear e progressista. Nessa perspectiva, o conhecimento matemático é visto como uma sucessão de descobertas matemáticas que são encadeadas linear e progressivamente até chegar a matemática moderna. Além disso, sua narrativa privilegia apenas os aspectos internos à própria área de conhecimento $\mathrm{e}$ os desdobramentos, que não são essencialmente matemáticos, são deixados de lado. (SAITO, 2015, p. 23).

Com base nessa explicação e nas considerações de Beltran, Saito e Trindade (2014) foram listadas como características de uma escrita da história da matemática baseada na vertente tradicional os seguintes itens: a) apresenta a história de forma linear e progressista; $b$ ) valoriza somente aspectos internos a própria matemática; c) descritiva; d) prioriza a evolução dos conceitos matemáticos deixando de lado questões que não sejam necessariamente matemáticas relacionadas ao contexto; e) propõe olhar o passado e selecionar apenas o que é familiar.

Visto isto, no que diz respeito a perspectiva historiográfica atualizada, entende-se que:

Diferentemente, as narrativas históricas mais atualizadas dedicam-se a compreender o processo de construção do conhecimento. Daí que as grandes narrativas são abandonadas para se dedicarem ao contexto em que os conhecimentos matemáticos são construídos. Desse modo, partindo do contexto em que o documento está inserido e a rede de relações matemáticas e extramatemáticas (isto é, sociais, políticas, econômicas, religiosas et.), o historiador procurar mapear os conhecimentos compartilhados pelo autor e por seus contemporâneos sem introduzir noções ou conhecimentos a eles alheios. Ao situar a matemática do passado no passado, buscando analisar cada etapa do desenvolvimento do conhecimento matemático 
segundo uma rede de relações devidamente contextualizadas, o historiador faz emergir do próprio processo histórico novas questões que dão acesso ao que são "conhecimento matemáticos" e "matemáticas" do passado. (SAITO, 2015, p. 28).

Assim, entende-se que uma escrita da história pautada nestes pressupostos apresenta de forma ampla o processo de desenvolvimento dos objetos de estudo da investigação, visto que essa historiografia busca realizar uma (re)construção no tempo e espaço, em consideração nesse processo não apenas informações internas a própria área do conhecimento.

A saber, listou-se como algumas das características da historiografia atualizada: a) visa contextualizar o conhecimento em seu tempo e espaço; b) procura (re)construir os saberes sem introduzir conceitos ainda alheios à época; c) tem como intenção partir do passado em direção ao presente; d) procura comtemplar as diferentes práticas não necessariamente matemáticas envolvidas no processo de construção do conhecimento; e) leva em consideração as circunstâncias na qual o conhecimento foi elaborado.

\section{Metodologia}

A partir das especificidades das historiografias aqui abordadas, de forma a identificar a aproximação das escritas baseadas na história da matemática presentes em livros didáticos do ensino médio com a vertente historiográfica tradicional e atualizada, foi realizada uma pesquisa qualitativa documental, como destacada por GODOY (1995). Para tanto, utilizou-se uma investigação dentre as oito coleções aprovadas pelo PNLD 2018 para trabalho com a matemática no ensino médio, selecionando a obra "Matemática: ciência e aplicações" de Iezzi et al. (2016), visto esta ser adotada em escolas da região Nordeste, possibilitando maior facilidade de acesso aos três volumes da coleção.

De acordo com Godoy (1995), feita a escolha do documento o passo seguinte na pesquisa qualitativa documental é a análise dos dados (conteúdos) que interessam ao estudo, a qual tem como etapas um momento inicial de pré-análise, posteriormente faz-se uma exploração e, por fim, apresenta-se um tratamento dos resultados. Cabe destacar que no presente artigo tal análise foi realizada nos textos em que a história da matemática é elucidada nos livros didáticos.

Nesse sentido, observou-se todas as páginas de cada volume a fim de identificar as escritas em que a história da matemática é evidenciada (pré-análise das escritas presentes na coleção). Mediante a verificação da quantidade de características em aproximação com uma das vertentes historiográficas. Cada escrita foi categorizada como tradicional ou atualizada 
(exploração das escritas presentes na coleção). Tentou-se ainda apresentar uma breve interpretação dos textos (tratamento dos resultados).

\section{Resultados}

A coleção "Matemática: ciência e aplicações" que está em sua nona edição composta de três volumes, os quais em sua disposição apresentam exemplos, exercícios resolvidos e propostos dentre outros elementos. Destes, destaca-se a seção em que a história da matemática é abordada, a qual é intitulada de "um pouco de história".

No que concerne a contextualização do conhecimento matemático presente no livro, motivo que a presença da história é eventualmente justificada nas coleções, verifica-se no guia de livros didáticos do PNLD 2018 que a obra "Matemática: ciência e aplicações" trás:

[...] contextualizações significativas que propiciam boas articulações com a história da Matemática, com práticas sociais extraescolares, com a própria Matemática e com outras áreas do saber, especialmente nas seções Um pouco de história, Troque Ideias e Aplicações. Tais atividades podem contribuir para despertar a curiosidade dos estudantes em relação aos temas trabalhados e para favorecer as reflexões sobre o papel do conhecimento matemático em diversos contextos. (BRASIL, 2017, p. 64).

Contudo, sob a intenção de identificar as escritas baseadas na história da matemática presentes nos livros da coleção mencionada, em estudo minucioso dos volumes, destacou-se as páginas em que o texto apresenta menção a elementos da história. Deste momento, tem-se a seguinte Tabela 1.

Tabela 1 - Páginas em que a escrita aborda a história da matemática

\begin{tabular}{c|c|c}
\hline Coleção & Volume & Páginas \\
\hline Matemática: & 1 & $33,49,152,192 / 193,211,214$ e 241 \\
\cline { 2 - 3 } Ciência e & 2 & $18,67,103,119,125 / 126,166$ e 253 \\
\cline { 2 - 3 } aplicações & 3 & $07 / 08,87,96 / 97,178 / 179$ e 219 \\
\hline \multicolumn{2}{|c}{ Fonte: Elaborada pelos autores }
\end{tabular}

Assim, nota-se que no conjunto dos três volumes são feitas 19 (dezenove) escritas que abordam a história da matemática, com uma maior quantidade para a obra destinada a alunos do $1^{\circ}$ ano. Visto isto, de maneira a orientar as observações em tais escritas, com base nas características da vertente historiográfica tradicional e atualizada elencadas em nosso referencial, elaborou-se a Tabela 2: 
Tabela 2 - Historiografias e suas características

\begin{tabular}{l|l|l|l}
\hline \multicolumn{2}{c|}{ Historiografia tradicional } & \multicolumn{2}{c}{ Historiografia atualizada } \\
\hline a) & $\begin{array}{l}\text { Apresenta a história de forma linear e } \\
\text { progressista }\end{array}$ & a) & $\begin{array}{l}\text { Visa contextualizar o conhecimento em seu } \\
\text { tempo espaço }\end{array}$ \\
\hline b) & $\begin{array}{l}\text { Valoriza somente aspectos internos a própria } \\
\text { matemática }\end{array}$ & b) & $\begin{array}{l}\text { Procura (re)construir os saberes sem introduzir } \\
\text { conceitos ainda alheios à época }\end{array}$ \\
\hline c) & Descritiva & c) & $\begin{array}{l}\text { Tem como intenção partir do passado em direção } \\
\text { ao presente. }\end{array}$ \\
\hline d) & $\begin{array}{l}\text { Prioriza a evolução dos conceitos matemáticos } \\
\text { deixando de lado questões que não sejam } \\
\text { necessariamente matemáticas relacionadas ao } \\
\text { contexto }\end{array}$ & d) & $\begin{array}{l}\text { Procura comtemplar as diferentes práticas não } \\
\text { necessariamente matemáticas envolvidas no } \\
\text { processo de construção do conhecimento. }\end{array}$ \\
\hline e) & $\begin{array}{l}\text { Propõe olhar o passado e selecionar apenas o que } \\
\text { é familiar. }\end{array}$ & e) & $\begin{array}{l}\text { Leva em consideração as circunstâncias na qual } \\
\text { o conhecimento foi elaborado. }\end{array}$ \\
\hline
\end{tabular}

Fonte: Elaborada pelos autores

Diante de tais características, observou-se a escrita de todas as páginas listadas na Tabela 1, com o intuito de identificar sua aproximação com as historiografias em questão. Na Tabela 3 apresentada logo a seguir, expõe-se o verificado:

Tabela 3 - Aproximação da escrita em que a história é abordada no livro com a historiografia tradicional e atualizada

\begin{tabular}{|c|c|c|c|}
\hline Volume & $\begin{array}{l}\text { Aproxima-se da vertente } \\
\text { tradicional por meio } \\
\text { da }(\mathrm{s}) \text { seguinte }(\mathrm{s}) \\
\text { característica }(\mathrm{s}):\end{array}$ & $\begin{array}{l}\text { Página(s) em } \\
\text { que a história } \\
\text { é elucidada }\end{array}$ & $\begin{array}{c}\text { Aproxima-se da vertente } \\
\text { atualizada por meio } \\
\text { da(s) seguinte }(\mathrm{s}) \\
\text { característica(s): }\end{array}$ \\
\hline \multirow{7}{*}{1} & b); c);e) & 33 & - \\
\hline & a);b);c);d);e) & 49 & c) \\
\hline & a); c); e) & 152 & a) \\
\hline & a);b);c);d);e) & $192-193$ & - \\
\hline & a);b);c);e) & 211 & - \\
\hline & a);b);c); e) & 214 & e) \\
\hline & c); e) & 241 & - \\
\hline \multirow{7}{*}{2} & b); c); e) & 18 & - \\
\hline & a);b);c);d);e) & 67 & - \\
\hline & a); b); c); d); e) & 103 & - \\
\hline & a);b);c);d);e) & 119 & - \\
\hline & a); b);c); d); e) & $125-126$ & - \\
\hline & b);c);e) & 166 & - \\
\hline & a);b);c);d);e) & 253 & - \\
\hline \multirow{5}{*}{3} & a);b);c);d);e) & $07-08$ & c) \\
\hline & a);b);c); d);e) & 87 & - \\
\hline & a); b);c);d);e) & $96-97$ & - \\
\hline & a);b);c);d);e) & $178-179$ & - \\
\hline & a);b);c);d);e) & 219 & c) \\
\hline Total & 19 & 19 escritas & 0 \\
\hline
\end{tabular}

$$
\text { Fonte: Elaborada pelos autores }
$$

Do exposto, tem-se que as 19 escritas em que a história é abordada apresentam uma maior quantidade de características que se aproximam da vertente historiográfica tradicional. Nesse sentido, entende-se assim como destacado no guia de livros didáticos do PNLD 2018 que as abordagens contêm breves informações, priorizando a sucessão de contribuição de 
determinados personagens em seu tempo, passando dessa forma e ideia de progresso no desenvolvimento dos conceitos matemáticos.

No que se refere às poucas escritas em que se notou uma certa aproximação com características da vertente atualizada, cabe destacar que do jeito como exposta, ela possivelmente não se caracterize plenamente da maneira que tal historiografia pressupõe que se estabeleça, como no caso das listadas com o item c) tem-se uma intenção de partir do passado em direção ao presente, porém esse percurso se dá de forma linear e progressista.

Com o propósito de exemplificar como foram realizadas todas as observações nos 19 casos em que a história é elucidada, afim de indicarmos a aproximação de suas escritas com as cinco características listadas para cada vertente, destaca-se a seguir a que foi realizada sobre a página 219 do volume 3 da coleção analisada. O texto presente na obra apresenta-se na Figura 1 a seguir:

Figura 1 - Seção especial da coleção: um pouco de história

\section{UM POUCO DE HISTORI:}

\section{A resolução de equações}

Os primeiros registros encontrados sobre a resoluçăo de algumas equaçōes do $2^{\circ} \mathrm{grau}$ datam de, aproximadamente, 1700 a.C. e pertencem a civilizaçōes antigas, como a dos sumérios, egipcios e babilônios.

Os gregos usaram a Geometria para aperfeiçoar as técnicas de resolução das equaçōes do $2^{\circ} \mathrm{grau}$.

A civilizaçăo islâmica também deixou um legado importante: a obra Al-jabr W'al- Mugabala, do matemático e astrónomo AI-Khowarizmi, datada do século VIII, inclui, entre outros, uma exposiçăo completa da resoluçăo das equaçōes do $1^{\circ} \mathrm{e} 2^{\circ}$ graus. A palavra "álgebra" deriva desse nome.

No século XVI, com o Renascimento italiano, ocorreu um progresso significativo: a resoluçăo de equaçōes do $3^{\circ}$ grau $e$, como decorrência, de $4^{\circ}$ grau. A história da resolução dessas equaçōes envolve

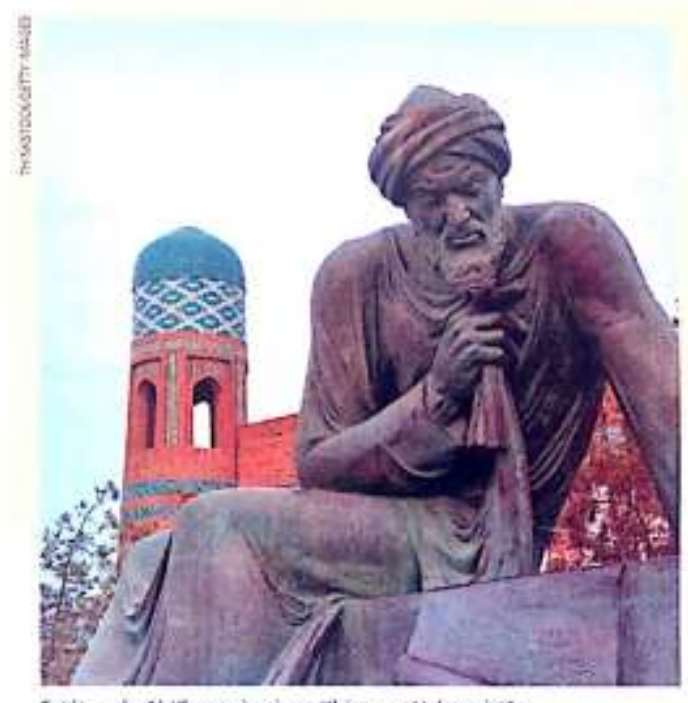

Estatua de A-Khowarizmi em Khiva, no Uzbenuistao. segredos, batalhas, desafios e traiçóes, culminando, em 1545, na publicaçăo de Ars Magna, de Girolamo Cardano. Essa obra contém o processo de resolução e a devida demonstração da fórmula de resolução de uma equação do $3^{0}$ grau, além da explicação de como resolver uma equaçăo do $4^{4} \mathrm{grau}$, transformando-a em outra do $3^{\circ} \mathrm{grau}$.

Durante dois séculos e meio tentou-se encontrar uma fórmula resolutiva para a equaçăo do $5^{\circ}$ grau. Somente em 1824 o norueguês Niels Abel (1802-1829) provou, de maneira consistente, a impossibilidade de resolução dessa equação por meio das quatro operaçôes aritméticas e de radiciaçōes.

Poucos anos depois, o francès Évariste Galois (1811-1832) - cujos trabalhos deram inicio à chamada Algebra Moderna - generalizou as condiçôes de resolubilidade de uma equaçâo algébrica qualquer. 
$\mathrm{Na}$ leitura realizada foi identificado que existe aproximação de tal escrita com todas as cinco características da vertente tradicional elencadas a partir das considerações de Beltran, Saito e Trindade (2014) e das de Saito (2015) e apenas uma da historiografia atualizada. Tal resultado é decorrente das seguintes observações:

No que se refere a escrita baseada nos moldes de uma historiografia tradicional o item a) foi elencado por ser possível notar uma certa linearidade nos fatos históricos dispostos no texto, visto que nele parte-se indicando de onde surgiram os primeiros registros e em seu decorrer vai apresentando novas informações que soam como uma ideia de sucessão e progressão de fatos.

Já a indicação do item b) como outra característica, se fez devido à disposição das informações no texto, encontram-se apenas aspectos internos a própria matemática. Prova disso é que em tal escrita, ao destacar o aperfeiçoamento das técnicas de resoluções de equações, não é empreendida qualquer menção que não seja especificamente matemática a elementos que estavam influenciado a necessidade desse aprimoramento.

Com base nas considerações de Saito (2015) o item c) também foi elencado como uma das características dessa escrita, pois ela está realizada de forma meramente descritiva. Ou seja, a apresentação das informações históricas não é realizada uma reflexão crítica sobre os elementos presentes em tal abordagem.

O item d) também está contemplado, pois na referida historiografia é priorizado apenas o progresso, a resolução de equações de um grau menor a outro cada vez maior e durante essa linearidade não foi levada em consideração nenhuma questão referente a outros conhecimentos que nos revelassem aspectos de seu contexto de desenvolvimento. Também foi identificado certa aproximação da escrita com o item e), pelo fato de apresentar apenas o que hoje nos é familiar como por exemplo o caso das equações de $2^{\circ}$ grau, $3^{\circ}$ grau, $4^{\circ}$ grau e $5^{\circ}$ grau.

No que se refere a uma não aproximação com as características da vertente historiográfica atualizada listadas conforme o destacado por Beltran, Saito e Trindade (2014) e por Saito (2015), o item a) não foi indicado, porque tal escrita não apresenta uma contextualização dos fatos que venha a favorecer uma compreensão do processo de construção e elaboração das determinadas equações.

Por sua vez, o item b) não foi identificado na escrita por conta da falta de elementos historiográficos, epistemológicos e contextuais da história da matemática que corroborassem para o estabelecimento de uma reconstrução dos conceitos incorporados pelas equações explanadas. 
Quanto ao item c) foi observado aproximação da escrita no sentido de que o texto parte dos primeiros registros de resolução de equações de $2^{\circ}$ grau até chegarem a de $5^{\circ}$ grau. Contudo, cabe destacar que a proposta fidedigna dessa característica da historiografia atualizada, segundo Saito (2015), é partir do passado em direção ao presente, mas no sentido de reconstruir determinados conhecimentos em seu tempo e espaço sem atribuir noções que hoje reconhecemos. O distanciamento do texto ao item c) começa a se evidenciar a partir do momento em que foram indicados os conhecimentos matemáticos praticados pelos egípcios como sendo os primeiros registros de resolução de equações do $2^{\circ}$ grau, sendo que está definição só foi estabelecida tempos depois.

A característica d) não foi listada devido à inexistência de informações que possibilitassem perceber a influência de outras práticas não necessariamente matemáticas no processo de desenvolvimento das considerações inicias sobre as equações de $2^{\circ}$ grau até ao estabelecimento das de $5^{\circ}$ grau descritas no texto. $\mathrm{O}$ item e) também não foi elencado, pois não se notou qualquer referência quanto às circunstâncias nas quais as equações eram resolvidas.

Considerações semelhantes permitiram a identificação das duas abordagens de escrita da história presentes nos livros da coleção destinada ao ensino médio apresentadas na tabela 03. No entanto, teve evidência as escritas com a vertente historiográfica tradicional e um distanciamento quanto à atualizada.

\section{CONSIDERAÇÕES FINAIS}

É fato que a história da matemática está presente em escritas de algumas das páginas do livro didático do ensino médio. Contudo, tal abordagem tem sido indicada por meio de breves informações que valorizam a sucessão de descobertas, os principais personagens e levam em consideração apenas aspectos internos a própria área, deixando de lado questões não necessariamente matemáticas do contex to de desenvolvimento dos conceitos (escrita da história baseada em algumas das características da vertente tradicional).

Uma escrita em que se possa observar o conhecimento matemático em seu tempo e espaço sem atribuir a ele conceitos ainda alheios aquela época e que permita incidir sobre ela reflexão crítica sobre as circunstâncias que influenciaram o processo de construção do conhecimento (escrita da história baseada em algumas das características da historiografia atualizada) não é apresentada nos livros didáticos do ensino médio.

Assim, não foi realizada uma investigação afim de mencionar se a escrita em que a história é versada no livro como critério para estabelecer a contextualização do conhecimento 
matemático pode de fato favorecer o processo de ensino e aprendizagem. Contudo, espera-se que esse estudo venha a ser tomado como aporte para possibilitar que os professores reflitam sobre esse tipo de escrita presente nos livros e a dimensão que podem dar a ela em suas aulas.

\section{REFERÊNCIAS}

BARONI, R. L. S.; NOBRE, S. R. A Pesquisa em História da Matemática e suas relações com a Educação Matemática. In: BICUDO, M. A. V. Pesquisa em Educação Matemática: Concepções \& Perspectivas. São Paulo: Editora Unesp, 1999. p. 129-136.

BELTRAN, M. H. R.; SAITO, F.; TRINDADE, L. dos S. P. História da ciência para formação de professores. São Paulo: Livraria da Física, 2014.

BIANCHI, M. I. Z. Uma reflexão sobre a presença da história da matemática nos livros didáticos. 2006. 103 f. Dissertação (Mestrado na área de Concentração em Ensino e Aprendizagem da Matemática e seus Fundamentos Filosófico-Científicos) - Universidade Estadual Paulista, Rio Claro, 2006.

BIFFI, L. C. R. História da Matemática nos Livros Didáticos do Ensino Médio: Uma Investigação. In: XX Encontro Brasileiro de Estudantes de Pós-Graduação em Educação Matemática (EBRAPEM), 2016, Curitiba. GD 5 - História da Matemática/Educação Matemática. Curitiba, 2016.

BRASIL. Secretária de Educação Básica. Guia de livros didáticos: PNLD 2018: matemática: ensino médio. Brasília: MEC/SEB, 2017.

CARDOSO, E. J.; ZUIN, E. de S. L. Equações quadráticas nos livros didáticos de Matemática: ainda "Fórmula de Bhaskara"?. In: XI Seminário Nacional de História da Matemática, 11, 2015, Natal/RN. Anais do XI Seminário Nacional de História da Matemática. Natal/RN: SBHMat, 2015.

CHAQUIAM, M. Ensaios Temáticos História e Matemática em sala de aula. Belém: Sbem/Sbem-pa, 2017.

GODOY, A. S. Pesquisa Qualitativa Tipos Fundamentais. Raje-revista de Administração de Empresas, São Paulo, v. 35, n. 3, p.20-29, 1995. Disponível em: < http://www.scielo.br/pdf/rae/v35n3/a04v35n3.pdf>. Acesso em: 15 maio 2018.

IEZZI et al. Matemática: ciência e aplicações. Obra em três volumes para os $1^{\circ}, 2^{\circ}$ e $3^{\circ}$ anos do ensino médio. $9^{a}$ ed. São Paulo: Saraiva, 2016.

OLIVEIRA, F. W. S.; SOUSA, A. C. G. de. Concepções de professores de matemática sobre o uso da história no ensino. 2017. 70 f. Trabalho de conclusão de curso (Graduação em Licenciatura em Matemática) - Instituto Federal de Educação Ciência e Tecnologia do Ceará, Canindé, 2017.

PEREIRA, E. M. História da Matemática nos livros didáticos de Matemática do Ensino Médio: conteúdos e abordagens. 2016. 91 f. Dissertação (Mestrado Profissional em Ensino de Ciências e Matemática) - Universidade Federal de Itajubá, Itajubá, 2016. 
SAITO, Fumikazu. História da matemática e suas (re)construções contextuais. São Paulo: Livraria da Física, 2015.

TURÍBIO, S. R. T.; SILVA, A. C. da. A influência do livro didático na prática pedagógica do professor que ensina matemática. Revista Prática Docente, Mato Grosso, v. 2, n. 2, p. 158178, 2017. Disponível em:

$<$ http://periodicos.cfs.ifmt.edu.br/periodicos/index.php/rpd/article/view/73/30>. Acessado em: 20 jun. 2018.

VIDAL et al. Reflexões sobre a história da matemática abordada nos livros didáticos do ensino médio: uma análise da história da estatística e dos números complexos. In: XII Encontro Nacional de Educação Matemática, 12, 2016, São Paulo. Anais do XII Encontro Nacional de Educação Matemática. São Paulo, 2016.

Recebido em: 16 de julho de 2018. Aprovado em: 28 de outubro de 2018. 